\title{
Current sensor based on Rogowski coil
}

\author{
F. J. Arcega ${ }^{1}$, J. A. Artero ${ }^{2}$ \\ ${ }^{1}$ Department of Electrical Engineering \\ Universidad de Zaragoza \\ María de Luna, 3- 50018 Zaragoza- Spain \\ Tfno (00) 34-976-762169 Fax (00) 34-976-762226, arcegafj@unizar.es \\ (1) Endesa Distribución - ERZ \\ C/ San Miguel 10, 50001 Zaragoza \\ Tfno. (00) 34976 760000, jartero@erz.es
}

\begin{abstract}
We have built several Rogowski coil current sensors for measuring currents in non sinusoidal systems. In this paper we present the sensor and his behavior. We have built a generator of pulses in order to test it and we compare the results between two types of coils (flexible and Printed Circuit board PCB designed) and the linearity for measuring currents
\end{abstract}

\section{Key words}

Rogowski coil, current sensor, electrical measurements

\section{Introduction}

Current sensors based in Rogowski coil is an innovative measuring system that offers advantages [1,2,3] with respect to conventional systems based in transformers with magnetic core. Their use has increased very recently in applications in Power Electronics [4], in Relay Protection [5,6] or in Transients [7].

The main characteristics of these sensors are the linearity, the large span and the bandwidth. So these sensors can be used in new applications related with high currents in non-sinusoidal systems.

The measuring principle is known since 1912. The Rogowski coil is a coil distributed uniformly in a non magnetic core that surround the conductor carrying the current to be measured, as indicated in the figure 1 .

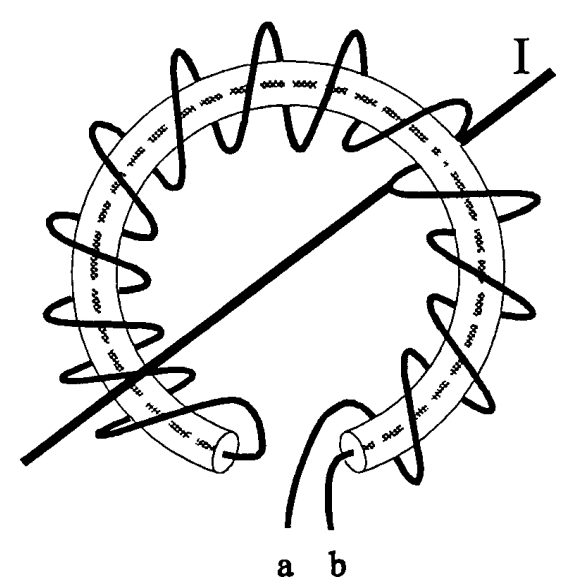

Fig. 1. Model of a Rogowski coil

The construction of a Rogowski coil presents some difficulties because for having some accuracy we need that the turns be equally distributed along the core and the return wire went back concentrically to avoid the external fields produced by external currents near the coil.

The most important characteristics of a Rogowski coil current sensor are::

- Large bandwidth allowing the measure of currents with fast transients as in the power distribution and power electronic circuits.

- Large span because with the same coil is possible to measure between some amps and some hundreds so kiloamperes.

- Good linearity because the coil is supported in a non magnetic material.

- No saturation, so the coil is not damaged by extra currents.

- Galvanic isolation between the primary circuit and the measuring circuit.

- The magnetic coupling between the primary circuit and the measuring circuit is only of several nanohenrys, so no charge effect. 
- Rogowski coil is better than conventional transformers in high frequency applications where the magnetic core disturb the linearity and is not useful

The basic disadvantage of the Rogowski coil is that the output is a voltage proportional to the derivative of the current crossing the coil and for obtaining the original signal, the output must be integrated by analog integrators or by digital signal processors (DSP).

Other work has been carried out by some of the authors in order to improve the measurement of high currents with the best accuracy for calibration applications [8,9] but magnetic core is the responsible of low linearity and some problems in high frequency.

\section{Rogowski coil}

If the electric current varies with the time, a magnetic flux is produced in the coil and applying the Ampere's law to the circuit of the figure 1 , we can obtain a voltage defined by

$$
V_{a b}=-\frac{d \phi}{d t}=-\mu_{0} \cdot \frac{N}{l} \cdot A \cdot \frac{d i}{d t}
$$

Where $\mathrm{N}$ is the total number of turns, A the area of the turn and 1 the average length of the toroid. For low frequencies the induced voltage could be of some milivolts if the current is of some tenths of amps, but it could be of some tenths of volts when currents change very fast (eg. $100 \mathrm{~A} / \mu \mathrm{s})$

We have built a coil of 2045 turns of wire of $0.4 \mathrm{~mm}$ of diameter obtaining a coil of $82 \mathrm{~cm}$. The diameter of the toroid is $7,22 \mathrm{~mm}$. The coil is shown in figure 2

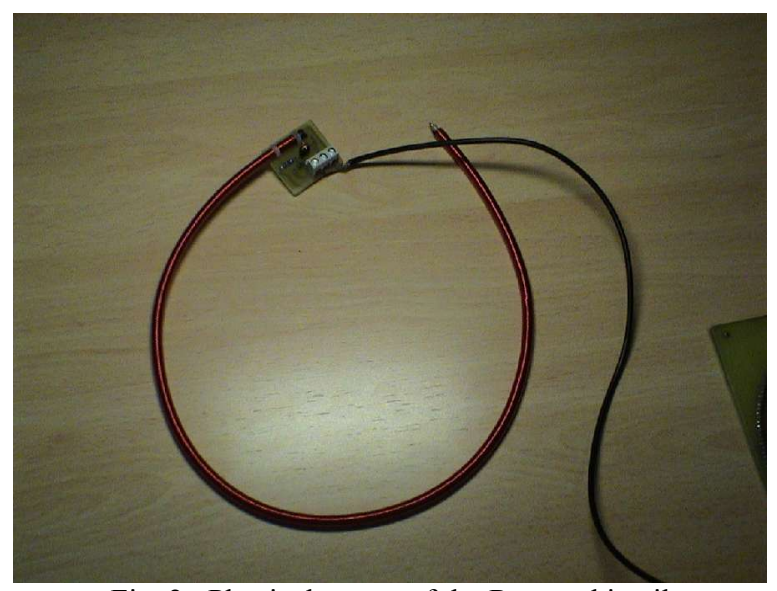

Fig. 2. Physical aspect of the Rogowski coil

We have built, as well, several PCB Rogowski coils where the surface and the separation between turns is fixed. Using the two sides of a circuit board is possible to obtain a rigid coil with well defined dimensions and characteristics. In the figure 3 we can see one side of the coil.

This coil has 100 turns with internal radius of $40 \mathrm{~mm}$ and external radius of $87,37 \mathrm{~mm}$ an inductance of $25 \mathrm{nH}$.
Instead of the return wire and for avoiding the noise and disturbances produced by external currents we have built a second coil equal to the first one and both are connected together but in opposition.

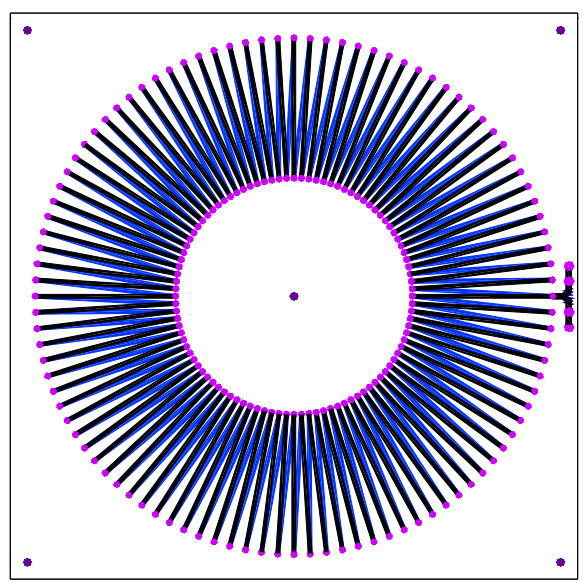

Fig. 3. Detail of PCB Rogowski coil

\section{Model for the Rogowski coil}

The behavior of a Rogowski coil can be simulated by a simple model, shown in the figure 4.

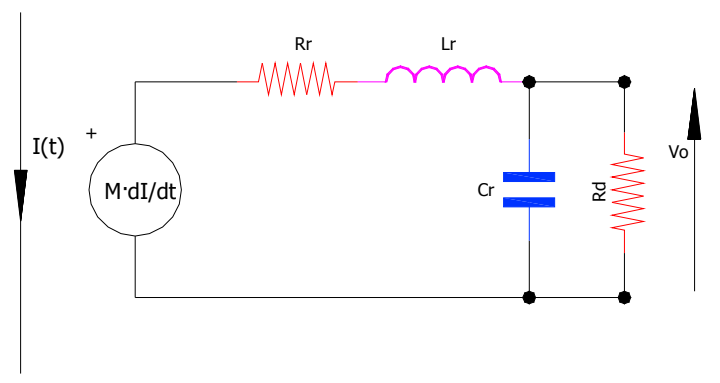

Fig. 4. Simplified model of the Rogowski coil

$\mathrm{R}_{\mathrm{r}}$ is the intrinsic resistance of the coil, $\mathrm{L}_{\mathrm{r}}$ is the distributed inductance of the coil and $\mathrm{C}_{\mathrm{r}}$ is the stray capacitance. $R_{d}$ is the resistance connected to the end of the coil for a correct measurement.

The transfer function of the circuit of the figure 3 is

$$
\frac{V_{o}(s)}{I(s)}=\frac{M \cdot s}{T_{b}^{2} \cdot s^{2}+2 \cdot \xi \cdot T_{b} \cdot s+1}(1)
$$

where

$$
\begin{aligned}
\text { - } T_{b} & =\sqrt{\frac{R_{d}}{R_{r}+R_{d}}} \sqrt{L_{r} \cdot C_{r}} \\
\text { - } \quad \xi & =\frac{1}{2} \sqrt{\frac{R_{d}}{R_{r}+R_{d}}} \cdot\left(R_{r} \cdot \sqrt{\frac{C_{r}}{L_{r}}}+\frac{1}{R_{d}} \cdot \sqrt{\frac{L_{r}}{C_{r}}}\right) \\
\text { - } M & =\mu_{0} \cdot \frac{N}{l} \cdot A
\end{aligned}
$$


Typical values for $\mathrm{M}$ could be between 20 and $100 \mathrm{nVs} / \mathrm{A}$, for $\mathrm{L}_{\mathrm{r}}$ between $20 \mu \mathrm{H}$ and $150 \mu \mathrm{H}$. For the stray capacitance the values could be between $30 \mathrm{pF}$ and $60 \mathrm{pF}$.

For our flexible coil, the electric characteristics are :

Resistance $6.2 \Omega$

Inductance $220 \mu \mathrm{H}$

Capacitance $45 \mathrm{pF}$

Coefficient M $0.1283 \mu \mathrm{Vs} / \mathrm{A}$

Those values for the coil permit us to measure with a bandwidth between 2 and $6 \mathrm{MHz}$. Values higher than the corresponding for the current transformers with magnetic core.

In figure 5 we can see the output voltage obtained by one of the prototypes of the coil as a response to an input current surge of type of rise time of 500ns, (the resistance $\mathrm{R}_{\mathrm{d}}$ was not connected in this case neither the integrator)

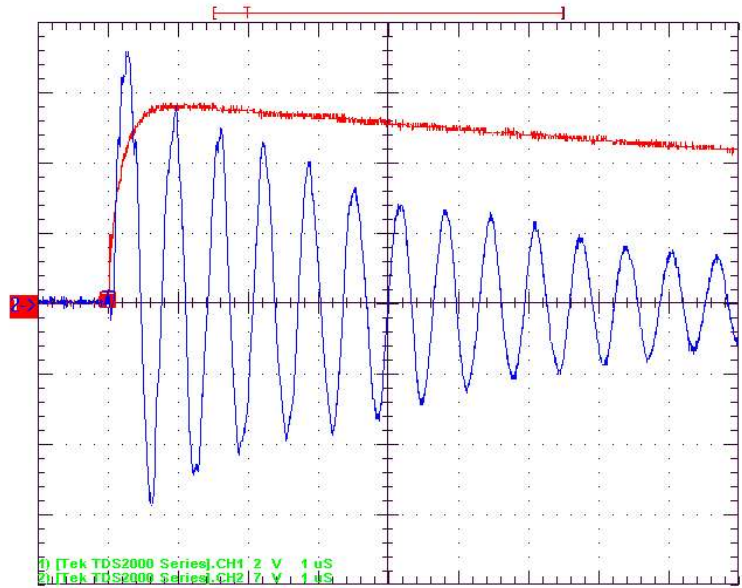

Fig. 5. Output voltage of the Rogowski coil (oscillatory) and current input (in dark)

The output voltage obtained in the coil is in accordance with the transfer function given by (1), and considering that $\mathrm{Rd} \rightarrow \infty$. The oscillation frequency and the decay factor depend on $\mathrm{R}_{\mathrm{r}}, \mathrm{L}_{\mathrm{r}} \mathrm{y} \mathrm{C}_{\mathrm{r}}$.

\section{Integrator circuit}

For obtaining the original current wave shape we need to integrate the signal in the output of the Rogowski coil. We can use integrator stages based on operational amplifiers (OA) with the appropriate bandwidth for the frequency of the current to be measured and a low noise level, because to a frequency of $50 \mathrm{~Hz}$ the output voltage of a Rogowski coil is of the order of several $\mu \mathrm{V} / \mathrm{A}$

The characteristic of an analog integrator is that the gain raises when the frequency diminish, so the random noise of low frequency and the noise coming from the offset must be attenuated by a filter so the characteristic gainfrequency for the integrator that we have built is shown in figure 6.

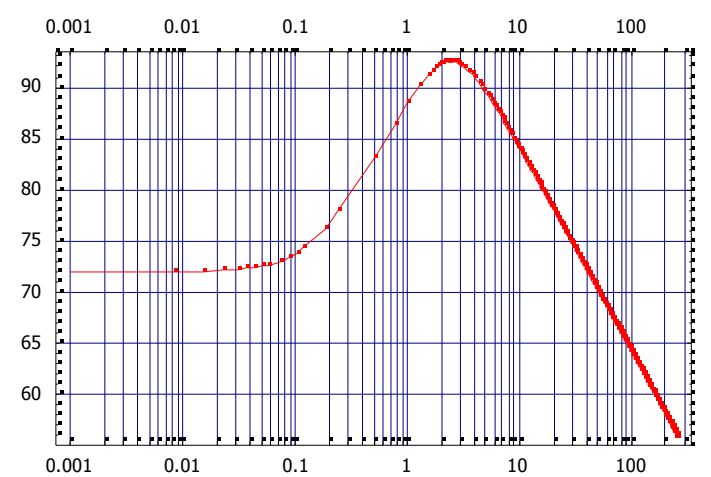

Fig. 6. Relationship between gain $(\mathrm{dB})$-frequency $(\mathrm{Hz})$ for the analog integrator

Another way to built an integrator is using a digital signal processor (DSP). In that case the DSP convert the signal from analog to digital, then filter it and later convert it again from digital to analog with the advantage of the flexibility to use different kinds of filters.

\section{Experimental results}

We have tested two coils one flexible coil and another PCB type in order to verify the linearity in a large range of currents.

As shown in figure 7 we can see that for both sensors the output is very linear from several amps to 750 amps. In both cases the error in linearity is lower than $0.8 \%$.

The only difference between the two coils is the coefficient that gives the proportionality between current and voltage because of the electronic circuits.

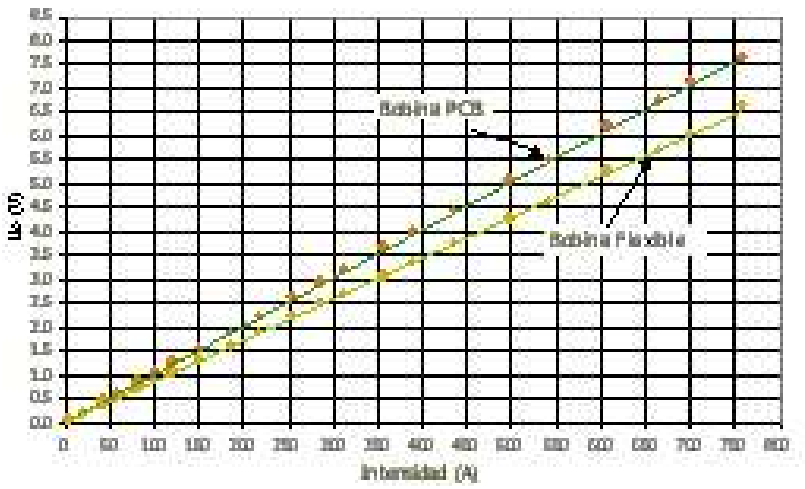

Fig. 7. Results of the linearity for both coils

With respect to the ability to detect fast transients the two kind of coils work well with the surge but due to the fact that the PCB has a lower value of the inductance is expected that higher bandwidth will be obtained.

In figures 8 and 9 we show the behaviour of the coils with a surge pulse. 


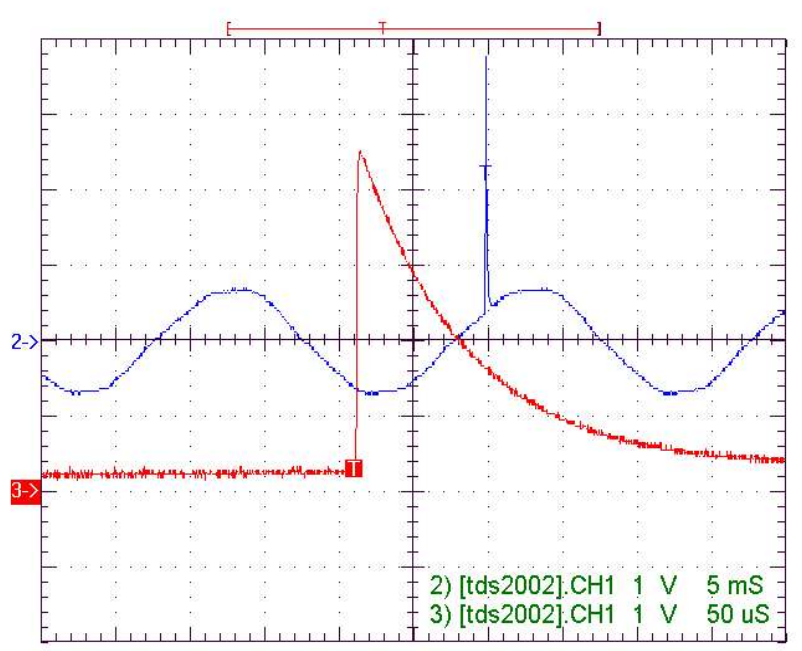

Fig. 8. Sinusoidal signal with a surge pulse detected with our Rogowski coil ( $1 \mathrm{~V}$ and $5 \mathrm{~ms}$ and $50 \mu \mathrm{s}$ )

\section{Conclusion}

We have designed and built a Rogowski coil with the electronic integrator able to measure electric currents with transients as shown in figure 6 . We have tested the coils in order to improve their behavior and linearity.

The idea is to use the coil for protection and measurement in power generation or in distribution. In particular for measuring the disturbances produced in power electric distribution or in power plants $[10,11,12]$.

Another possibility that we are considering is the use of the coil for the fast detection of failures in distribution systems

In a future work we are considering the improvement of the knowledge of the errors produced by other currents flowing near the sensor.

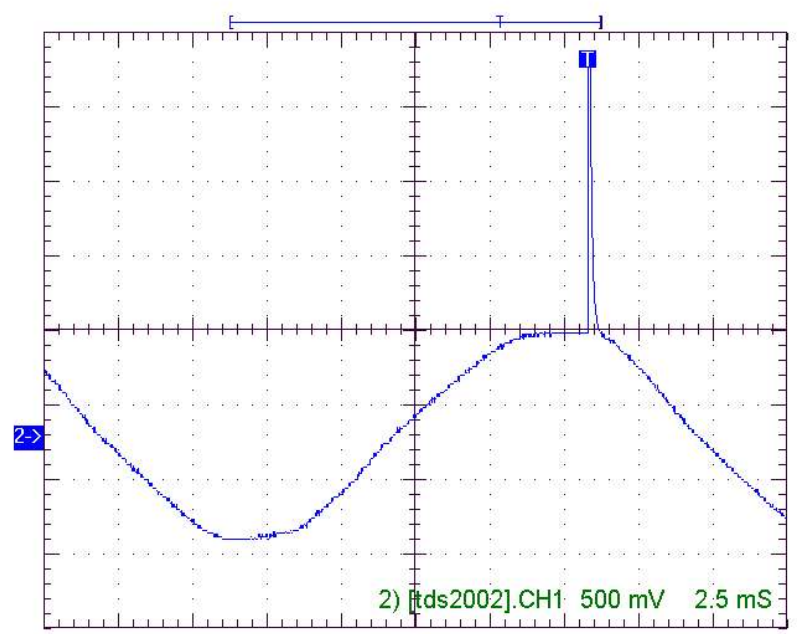

Fig. 9. Sinusoidal signal with a surge pulse detected with our Rogowski coil (500 mV and $2.5 \mathrm{~ms}$ )

We have tried to present in the paper a comparative between different coils that we are building, for selecting the best coil with more accuracy for future applications. The work continues with studies of the position of the external conductors and internal conductors carriyng currents with respect to the coil.
Two more fields of work are open, the first one the simulation with finite element method of the rogowski coil for improving the design of more performant coils and the second theknowledge in the laboratory for reduce the effects of other conductors in the vicinity in the measurements.

\section{Acknowledgement}

We aknowledge the Laboratory of Electrical Measurements (LME) of the University of Zaragoza for the use of the facilities for having high currents..

\section{References}

[1] W. F. Ray \& C.R. Hewson. "High performance Rogowski current transducers". Power Electronic Measurements Ltd. 2000

[2] Paulo Márcio da Silveira \& Carlos Alberto Mohallem Guimaraes. "Novos transdutores de corrente e de potencial em alta tensao: estado da arte, tendências e aplicaçoes. XIV Seminario Nacional de produçao e transmissao de energia elétrica, Brasil 1997

[3] W. Koon. "New developments in solid state current sensors". Applications Engineer, Energy Measurement Group, Analog Devices. Tecnologías unidas, Tecun, Ltda. 1999

[4] Nicolas Karrer \& Patrick Hofer-Noser. "A new current measuring principle for power electronic applications". Electrical Engineering and design lab (EEK), Swiss Federal Institute of Technology, Zürich. 1999

[5] Ljubomir Kojovic. "PCB Rogowski Coils Benefit Relay Protection". IEEE Computer Aplications in Power, July 2002

[6] Ljubomir Kojovic. "High-Precision Rogowoski Coils for Improved relay protection, control and measurements". Cooper Industries, Inc. Bulletin number 02049. 2002

[7] D. A. Ward \& J. La T. Exon. "Using Rogowski coils for transient current measurements". Engineering science and education journal, June 1993.

[8] M. Samplon and others, "Uncertainties associates with clamp-type current meters analysis by the finite element method" ISEM 03 International Symposium on Applied Electromagnetics and Mechanics, Paris (France) may 2003.

[9] A. Uson and others, "An examination of current measurements deviation when using rectangular crosssection conductors" CLEEE`03, 8th Portuguese-Spanish Congress in Electrical Engineering, Villamoura (Portugal)

[10] R. Gross, H.J. Herrmann, U. Katschinski, P. Menke, A. Ostermeier, J. Schmid, M. Wache. "Substation control and protection system for novel sensors". Cigré 12/23/3403 del año 2000.

[11] E. Echevarria. "Medición de grandes intensidades. Intercomparación de laboratorios". VI jornadas internacionales de aislamiento. Zamudio 1997.

[12] Christian Teyssandier. "From current transformer to hybrid sensors, in HV". Cahier Technique Merlin Gerin n ${ }^{\circ}$ 170. March 1995. 